\title{
Utilizing ethacrynic acid and ciclopirox olamine in liver cancer
}

\author{
AHMAD M. AL-DALI ${ }^{1,2}$, HANS WEIHER ${ }^{2}$ and INGO G.H. SCHMIDT-WOLF ${ }^{1}$ \\ ${ }^{1}$ Center for Integrated Oncology, University Hospital Bonn, Bonn D-53105; ${ }^{2}$ Department of Immunology and Cell Biology, \\ Bonn-Rhein-Sieg University of Applied Sciences, Rheinbach D-53359, Germany
}

Received November 2, 2017; Accepted August 30, 2018

DOI: $10.3892 / \mathrm{ol} .2018 .9472$

\begin{abstract}
Once aberrantly activated, the Wnt/ $\beta$-catenin pathway may result in uncontrolled proliferation and eventually cancer. Efforts to counter and inhibit this pathway are mainly directed against $\beta$-catenin, as it serves a role on the cytoplasm and the nucleus. In addition, specially-generated lymphocytes are recruited for the purpose of treating liver cancer. Peripheral blood mononuclear lymphocytes are expanded by the timely addition of interferon $\gamma$, interleukin (IL)-1 $\beta$, IL-2 and anti-cluster of differentiation 3 antibody. The resulting cells are called cytokine-induced killer (CIK) cells. The present study utilised these cells and combine them with drugs inhibiting the Wnt pathway in order to examine whether this resulted in an improvement in the killing ability of CIK cells against liver cancer cells. Drugs including ethacrynic acid (EA) and ciclopirox olamine (CPX) were determined to be suitable candidates, as determined by previous studies. Drugs were administered on their own and combined with CIK cells and then a cell viability assay was performed. These results suggest that EA-treated cells demonstrated apoptosis and were significantly affected compared with untreated cells. Unlike EA, CPX killed normal and cancerous cells even at low concentrations. Subsequent to combining EA with CIK cells, the potency of killing was increased and a greater number of cells died, which proves a synergistic action. In summary, EA may be used as an anti-hepatocellular carcinoma drug, while CPX possesses a high toxicity to cancerous as well as to normal cells. It was proposed that EA should be integrated into present therapeutic methods for cancer.
\end{abstract}

\section{Introduction}

Hepatocellular carcinoma (HCC) is state of liver cancer where hepatocytes lose the ability of controlled growth and gain the ability to avoid apoptosis, due to a certain mutation. Its

Correspondence to: Professor Ingo G.H. Schmidt-Wolf, Center for Integrated Oncology, University Hospital Bonn, 25 Sigmund-Freud-Straße, Bonn D-53105, Germany

E-mail: ingo.schmidt-wolf@ukbonn.de

Key words: Wnt/ $\beta$-catenin, ethacrynic acid, ciclopirox olamine, cytokine-induced killer cells, hepatocellular carcinoma, interferon $\gamma$ prevalence being the sixth and the fact that it is the third most frequent cause of cancer-related death explain the reason why it grabs such attention (1). In addition to having very poor prognosis, its incidence is going higher worldwide mainly caused by the dissemination of hepatitis $\mathrm{B}$ and $\mathrm{C}$ virus infection $(2,3)$.

The methods for detection and treatment have been greatly improved in the last decade. Despite such a success in diagnosing $\mathrm{HCC}$, it is mostly diagnosed after reaching a late-stage tumour. At this point the survival time is quit short. The current options for therapy might not be appropriate at that time to intervene. Surgery is always the first choice, which is mostly convenient in early stages with no metastasis of the tumour (4). However, cancers in later stages and high invasive tumours are difficult to cure, and the recurrence chance is very high, thus the urgent need for novel treatment methods that are biologically-developed $(5,6)$.

There are 3 types of the Wnt/ $\beta$-catenin pathway, and only the canonical pathway will be discussed further in this study The relation between the Wnt/ $\beta$-Catenin pathway and cancer was first found in 1993 when an interaction between $\beta$-Catenin and adenomatous polyposis coli (APC) protein was observed. APC gene was previously discovered in familial adenomatous polyposis (FAP), a case of cancer (7).

In a screening for a wide variety of known drugs including anti-inflammatory drugs (NSAIDs), EA was shockingly able to inhibit the gene activity, while others could not. Although being used as a loop-diuretic for years, the anti-tumor ability is being well-used nowadays. It has been shown that EA can break apart the LEF-1/ $\beta$-catenin complex and has the ability to replace LEF-1, thus stopping the Wnt target gene transcription in CLL cells. In addition, the expression of LEF-1, cyclin D1 and fibronectin is greatly suppressed after the treatment with EA (8). The other important chemical agent in this study is CPX, which was originally used as an antifungal agent. In addition to being an iron chelating agent and its antibacterial and antimycotic abilities, it has been recently reported that CPX might be a strong candidate to fight cancer. The mechanism by which the inhibition works was revealed to be through downregulation of cyclin proteins expression as well as cyclin-dependent kinases (CDKs) (9).

In 1991, Ingo Schmidt-Wolf et al (10), developed a protocol which involves expanding T-lymphocytes to a new kind of cells that phenotypically express a mixture of $\mathrm{T}$ - and NK cells and having markers for both. These new cells are called cytokine-induced killer cells (CIK) cells. They are easily developed ex-vivo from peripheral blood mononuclear 
cells (PBMCs) by adding the IFN- $\gamma$, anti-CD3 mAb, IL-2, and IL-1 $\beta(10,11)$.

We aim to check if there is any increased killing when combining CIK cells with either drug, EA or CPX, against liver cancer cell lines using a cell viability assay.

\section{Materials and methods}

Cell lines and culture conditions. Hep3B and HepG2 cell lines (DSMZ, Braunschweig, Germany) and CCD18-co cell line (ATCC, Wesel, Germany) were incubated in aseptic optimal conditions as recommended; at $37^{\circ} \mathrm{C}$ with $5 \% \mathrm{CO}_{2}$ and $90 \%$ humidity in the incubator Cytoperm 2 (Thermo Fischer Scientific, Inc., Schwerte, Germany). The culture medium used was different. For HepG2 cell line, 90\% RPMI-1640 medium and $10 \%$ heat inactivated fetal bovine serum (FBS) was used. For Hep3B and CCD18 cells, 90\% EMEM containing $2 \mathrm{mM}$ L-glutamine and $10 \%$ heat inactivated (FBS) combination was used. In addition, $1 \%$ penicillin/streptomycin was added to each of the media.

CIK cells generation. Blood from healthy donors was acquired from Blutspendedienst Bonn-Venusberg, Germany. Blood samples were collected after approval by the Ethical Committee of the University of Bonn. In all cases informed consent was obtained and the experiments were conducted in agreement with the Declaration of Helsinki. $25 \mathrm{ml}$ of blood was added to $25 \mathrm{ml}$ of PBS (Thermo Fischer Scientific, Inc.) containing 1\% BSA (Sigma-Aldrich; Merck KGaA, Darmstadt, Germany). After that, $30 \mathrm{ml}$ of this mixture was pipetted very slowly on $15 \mathrm{ml}$ of Ficoll (Pan-Biotech, Aidenbach, Germany) with a density of $1.077 \mathrm{~g} / \mathrm{ml}$. This new $45 \mathrm{ml}$ containing tube was then centrifuged for $30 \mathrm{~min}$ at $4^{\circ} \mathrm{C}$ without break, in order to generate separate layers. The buffy coat later was aspirated using a pipette and transferred to a new tube that contains $10 \mathrm{ml} 1 \% \mathrm{PBS} / \mathrm{BSA}$, and filled up to $50 \mathrm{ml}$ with the same solution. A second centrifugation step at $320 \times \mathrm{g}$ for $7 \mathrm{~min}$ at room temperature was performed. Next, the supernatant was discarded and $10 \mathrm{ml}$ of the lysis buffer. It was prepared by dissolving $8.29 \mathrm{~g} \mathrm{NH}_{4} \mathrm{Cl}$ (Merck KGaA), $1 \mathrm{~g}$ $\mathrm{KHCO}$, and $0.037 \mathrm{~g}$ EDTA (both from Sigma-Aldrich; Merck $\mathrm{KGaA}$ ) in 11 distilled water. The pellet was resuspended and the tube was then placed on ice for $10 \mathrm{~min}$, in order to get rid of the red blood cells. Then, the tube was filled with $1 \%$ PBS/BSA up to $50 \mathrm{ml}$, and centrifuged at $320 \mathrm{xg}$ for $7 \mathrm{~min}$ at RT. After that, $2 \mathrm{ml}$ of CIK media was added, and the pellet was resuspended. CIK media was prepared by adding $10 \%$ FBS, 1\% Penicillin/Streptomycin (Thermo Fischer Scientific, Inc.), and $12.5 \mathrm{ml}$ of $1 \mathrm{M}$ Hepes to RPMI 1640 media (both from Pan-Biotech). $10 \mu \mathrm{l}$ of the suspension was used to count the cells. First, a 10 fold dilution step with $90 \mu 1$ PBS was needed because the count is too high. Second, $10 \mu \mathrm{l}$ of the diluted suspension was added to 90 trypan blue (Biochrome, $\mathrm{GmbH}$, Berlin, Germany), which makes another 10 fold dilution. Immediately, using normal light microscope and the improved Neumann chamber (Labor Optik, Lancing, UK) the cells were counted. Next, cells were seeded in a T-175 culture flask (Greiner Bio-One, Frickenhausen, Germany) at density of $75 \times 10^{6}$ cells, and then $40 \mathrm{ml}$ of CIK media was added. At the same day, $400 \mu 1$ of IFN $\gamma$ (BioLegend GmBH, Koblenz,
Table I. $\mathrm{IC}_{50}$ for EA and CPX against hepatocellular carcinoma cell lines and a control (CCD18).

\begin{tabular}{lcl}
\hline & \multicolumn{2}{c}{$\mathrm{IC}_{50} \mu \mathrm{M}$} \\
\cline { 2 - 3 } Cell line & $\mathrm{EA}$ & $\mathrm{CPX}$ \\
\hline Hep3B & 6.4 & 6.8 \\
HepG2 & 14.8 & 32.7 \\
CCD18 & 64 & 19.7 \\
\hline
\end{tabular}

$\mathrm{IC}_{50}$, half-maximal inhibitory concentration; EA, ethacrynic acid; $\mathrm{CPX}$, ciclopirox olamine.

Germany) with a concentration of $100 \mathrm{U} / \mu 1$ was added. On the next day, the cell suspension was removed and transferred to a new culture flask, in order to get rid of the adherent dendritic cells. In addition, $400 \mu \mathrm{l}$ of $\alpha$-CD3, $400 \mu \mathrm{l}$ of IL-1 $\beta$ (both from Thermo Fischer Scientific, Inc.) and 1,200 $\mu \mathrm{l}$ of IL-2 (BioLegend $\mathrm{GmBH}$ ) with working concentrations of $50 \mathrm{ng} / \mathrm{ml}$, $10 \mathrm{U} / \mu \mathrm{l}$, and $20 \mathrm{U} / \mu 1$ were added, respectively. All procedures were performed under sanitary conditions under laminar flow hood (Hood Series 1300 Class A2; Thermo Fisher Scientific, Inc.). CIK cells were stained with antibodies against CD3 and CD56 to prove the subset of NKT cells within the CIK cell culture (data not shown).

Drugs. EA was ordered from Sigma-Aldrich; Merck KGaA, while CPX was obtained from BIOZOL Diagnostica Vertrieb $\mathrm{GmbH}$ (Eching, Germany). The drugs were dissolved in $100 \%$ Ethanol (Thermo Fischer Scientific, Inc.). Aliquots of the original drug were prepared using PBS and frozen at $-20^{\circ} \mathrm{C}$. The range of concentrations was from $31.25 \mu \mathrm{M}$ till $3.0 \mathrm{mM}$. During the titration experiment, $10 \mu \mathrm{l}$ of the aliquot was pipetted into $90 \mu \mathrm{l}$ of media, which resulted in a 10 -fold dilution of the concentration.

Cell viability assay. The most common method to determine the viability of the cell has used to be the MTT assay. However, recently a new method has been introduced, which is much more sensitive than its preceding methods. This method is called WST- 8 assay (Water-Soluble Tetrazolium). In the presence of viable cells, the dehydrogenase enzyme converts the WST to a yellow-colored media-soluble formazan dye. In addition to being more sensitive, WST reagent is not toxic to the cells and does not require any preparation procedure (12). The cell counting kit was bought from Dojindo Molecular Technologies, Inc., (Munich, Germany). The protocol was followed as recommended in the manual. 2000 of each cell line were seeded in a 96 -well plate $24 \mathrm{~h}$ before the treatment. The measurement of the absorbance was performed 3-4 $\mathrm{h}$ after the addition of the WST reagent at $450 \mathrm{~nm}$.

IFN- $\gamma$ Enzyme-linked immunosorbent assay (ELISA). $5 \times 10^{5}$ cells were seeded in a 6 well plate, and $1 \mathrm{ml}$ of the media was added. Next day the media was aspirated, and replaced with fresh $750 \mu \mathrm{l}$ media. Then $5 \times 10^{6} \mathrm{CIK}$ cells were added as well as $750 \mu \mathrm{l}$ of CIK media, making the total volume of 

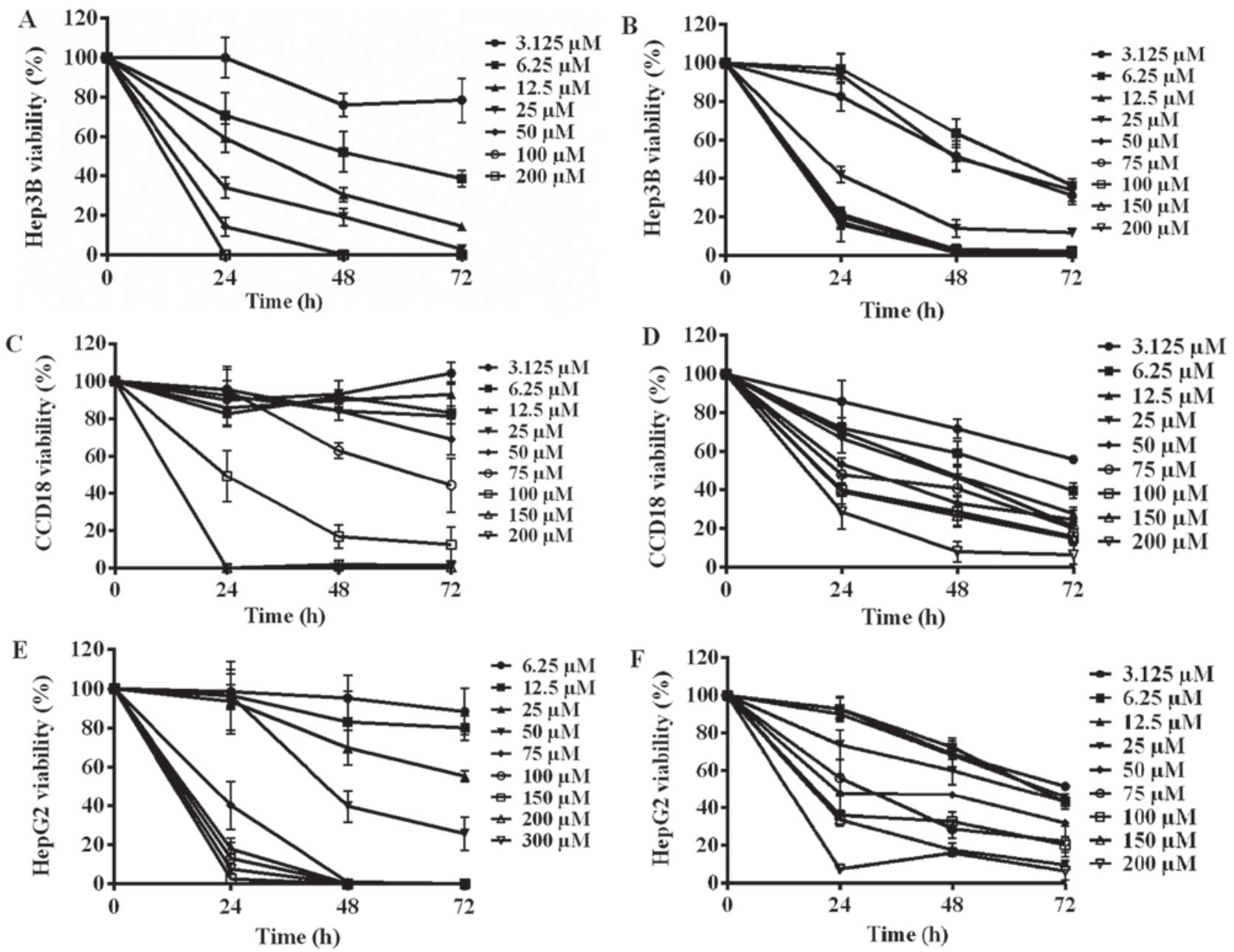

Figure 1. The effect of EA (Left side) and CPX (Right side) against (A and B) Hep3B, (C and D) HepG2 and (E and F) CCD18 cell lines. 2,000 cells were incubated for various amounts of time with increasing concentrations $(\mu \mathrm{M})$ of one drug, in a $37^{\circ} \mathrm{C}, 5 \% \mathrm{CO}_{2}$ incubator. A reversely proportional relationship can be observed in all graphs, although they differ in the intensity of responsiveness to the drugs. (A) With the exception of 100 and $200 \mu \mathrm{M}$, increasing the incubation time with EA resulted in lower viability of Hep3B cells. (B) CPX killed most of the Hep3B cells within the first day, and even low concentration caused significant cellular death. (C) Below $75 \mu \mathrm{M}$, EA did not affect CCD18 cells, affecting the viability at higher concentrations. (D) CPX, even in low concentrations resulted in severe CCD18 cellular loss. (E) EA had a killing effect on HepG2 cell line after $24 \mathrm{~h}$ of incubation starting from $75 \mu \mathrm{M}$ and higher and resulted in almost total death. During the next days, lower concentrations started having mild killing effects while concentration lower than 25 hardly had any effect. (F) CPX, even with very high concentration of CPX $(200 \mu \mathrm{M})$, was not efficient in achieving total cell death. The results shown are derived from measurements done in quadruplicates $(n=4)$. EA, ethacrynic acid, CPX, ciclopirox olamine.

each well $1.5 \mathrm{ml}$. The plate was incubated for 2 days. After that the media was aspirated into a $1.5 \mathrm{ml}$ Eppendorf tube and centrifuged at $14,000 \mathrm{~g}$ for $15 \mathrm{~min}$. Then the supernatant was transferred to a new tube and stored at $-20^{\circ} \mathrm{C}$ for later analysis. ELISA was performed using Human IFN-gamma DuoSet ELISA (R\&D Systems, Inc., Minneapolis, MN, USA). The protocol was followed as provided in the manual and nothing was changed.

Data analysis. WST assay data were exported as an excel file, where initial analysis took place. The cellular viability was calculated according to the following equation: (Absorbance of treated cells-absorbance of the blank) x100 Absorbance of untreated cells-absorbance of the blank

The resulting viability values were transferred to GraphPad Prism 6 v.6.01 (GraphPad Software, Inc., La Jolla, CA, USA), and the res ults were further analysed using two-way ANOVA with Tukey's multiple comparisons test as a post hoc test. $\mathrm{P}<0.05$ was considered to indicate a statistically significant difference. The number of experiments or measurements performed is indicated as (n). Data are represented as mean \pm standard deviation (SD).

\section{Results}

The effect of EA and CPX on the cellular viability. Fig. 1 demonstrates the relationship between the concentration of the drug and the viability of the cells. An inversely proportional relationship between the concentration of EA and the viability of Hep3B cells can be seen. Furthermore, by increasing the incubation time from 1 to 3 days, more cells were killed, with the exception of 100 and $200 \mu \mathrm{M}$, since all the cells died in the first day (1A). In comparison to EA, lower CPX concentrations are needed to kill the same number of Hep3B cells. Starting from $50 \mu \mathrm{M}$ up to $200 \mu \mathrm{M}$ almost all the cells were killed during the first day, with no viable remaining cells in the second or third day. CPX acted in a dose and time dependent manner as well, but much 

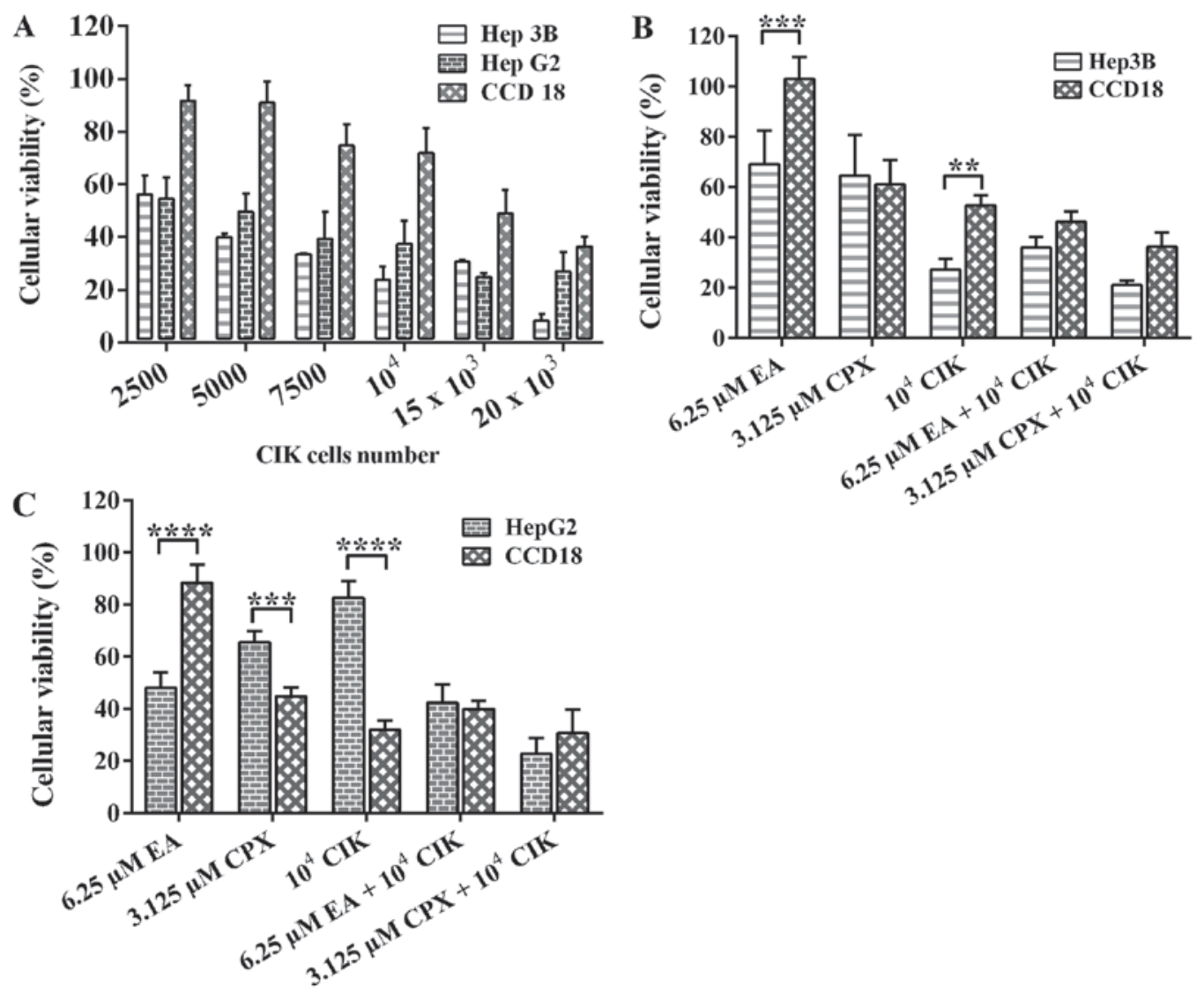

Figure 2. The effect of CIK cells on HCC cells. (A) Titration process of CIK cells where various numbers of mature 10 days old CIK cells were incubated with 2,000 cancer or control cells for $48 \mathrm{~h}$ in a 96-well plate. Cells were incubated for $48 \mathrm{~h}$. Combination experiment with one drug and CIK cells on Hep3B (B) and HepG2 (C) cell lines. $\mathrm{P} \leq 0.05,{ }^{* *} \mathrm{P} \leq 0.01,{ }^{* * *} \mathrm{P} \leq 0.001,{ }^{* * * *} \mathrm{P} \leq 0.0001$. CIK, cytokine-induced killer; HCC, hepatocellular carcinoma.

more potent than EA (1B). In regard to the control cell line CCD18 and the drugs, it is evident that EA did not affect the cells in concentration under $75 \mu \mathrm{M}$. Nevertheless, it has caused cellular death at extremely higher concentrations (1C). In contrast, CPX sustained the killing ability regardless of the fact that the cells are not cancerous. CPX even in very low concentration resulted in decreased viability (1D). Furthermore, it can be concluded that EA had a killing effect on $\mathrm{HepG} 2$ cell line after $24 \mathrm{~h}$ of incubation starting from $75 \mu \mathrm{M}$ and higher and resulted in almost total death. During the next $48 \mathrm{~h}$, the lower concentration 50 and $25 \mu \mathrm{M}$ had mild killing ability while concentration lower than 25 barely had a noticeable effect (1E). Compared to EA, CPX expressed more time and dose dependent behavior and maintained constant killing increment. However, even with very high concentration of CPX $(200 \mu \mathrm{M})$, total cell death has not been achieved $(1 \mathrm{~F})$. The IC50 values were gathered and presented in Table I.

The effect of CIK cells on the cellular viability. After incubating different numbers of CIK cells with each cell line for $48 \mathrm{~h}$, the results were collected and depicted in Fig. 2A. As seen, Hep3B cell line was the least resistant and the one to have more dead cells. Nevertheless, HepG2 were also killed in an increasing manner as well. In contrast, CCD18 normal human fibroblasts, used as a control, were slightly affected and did not die significantly until incubated with very high numbers of CIK cells $(20 \mathrm{~K})$.
The effect of EA on CIK cells viability. It has been pointed out by Schmidt et al (13), that $30 \mu \mathrm{M}$ of EA was sufficient to significantly affect cancer cell lines, while having minumun effect on PBMCs. Since CIK cells are a specific type of PBMCs, we expected the same result in our experiment. On the other hand, the effect of CPX has never been reported or tested.

The effect of either drug combined with CIK cells. As shown in Fig. 2B, the effect of EA and CPX incubated alone on Hep3B cell line results in 60 to $70 \%$ viability, while CIK cells results in viability around $30 \%$. Furthermore, once added in combination, EA and CIK cells resulted in decreased viability as low as $40 \%$, while CPX and CIK cells yielded only $20 \%$. In other words, the killing was increased once added in combination rather than separately. The figure also shows that there is a significant difference between the effect on cancer cells and normal human fibroblasts. They were not affected by EA alone, and a combination of EA and CIK cells resulted in 55\% viability. Regarding HepG2 cell line, EA and CPX caused cellular death giving 60 and $70 \%$ viable cells respectively (Fig. 2C). CIK cells were not as effective in killing because they killed only $20 \%$ of the cells. However, once combined with either EA or CPX, the viability dropped drastically to 40 and 20\% respectively. Regarding CCD18 normal fibroblasts, EA had no significant killing. In contrast, CPX had a severe effect and killed $60 \%$ of the cells. Tables II and III show the mean and the standard deviation values for the parameters presented in Figs. 2B and C, respectively. 
Table II. Mean and SD of cell viability of HCC and control group cells treated with EA, CPX and CIK.

\begin{tabular}{lrrrr}
\hline & \multicolumn{2}{c}{ Hep3B cell viability } & \multicolumn{2}{c}{ CCD18 cell viability } \\
\cline { 2 - 3 } Treatment & Mean & SD & Mean & SD \\
\hline $25 \mu \mathrm{M} \mathrm{EA}$ & 69.17 & 13.3 & 103.05 & 8.65 \\
$12.5 \mu \mathrm{M} \mathrm{CPX}$ & 64.65 & 16.2 & 61.10 & 9.78 \\
$10^{4} \mathrm{CIK}$ & 27.28 & 4.2 & 52.79 & 4.00 \\
$25 \mu \mathrm{M} \mathrm{EA}+10^{4} \mathrm{CIK}$ & 36.08 & 4.1 & 46.22 & 4.14 \\
$12.5 \mu \mathrm{M} \mathrm{CPX}+10^{4} \mathrm{CIK}$ & 21.11 & 1.8 & 36.32 & 5.74 \\
\hline
\end{tabular}

HCC, hepatocellular carcinoma; SD, standard deviation; EA, ethacrynic acid; CPX, ciclopirox olamine; CIK, cytokine-induced killer cells.

Table III. Mean and SD of cell viability of HCC and control group cells treated with EA, CPX and CIK.

\begin{tabular}{llccr}
\hline & \multicolumn{2}{c}{ HepG2 cell viability } & \multicolumn{2}{c}{ CCD18 cell viability } \\
\cline { 2 - 3 } Treatment & Mean & SD & Mean & SD \\
\hline $25 \mu \mathrm{M} \mathrm{EA}$ & 48.05 & 5.94 & 88.44 & 6.77 \\
$12.5 \mu \mathrm{M} \mathrm{CPX}$ & 65.55 & 4.27 & 44.80 & 3.42 \\
$10^{4} \mathrm{CIK}$ & 82.62 & 6.38 & 31.90 & 3.63 \\
$25 \mu \mathrm{M} \mathrm{EA}+10^{4} \mathrm{CIK}$ & 42.32 & 7.00 & 39.95 & 3.13 \\
$12.5 \mu \mathrm{M} \mathrm{CPX}+10^{4} \mathrm{CIK}$ & 22.66 & 6.20 & 30.74 & 8.96 \\
\hline
\end{tabular}

HCC, hepatocellular carcinoma; SD, standard deviation; EA, ethacrynic acid; CPX, ciclopirox olamine; CIK, cytokine-induced killer cells.

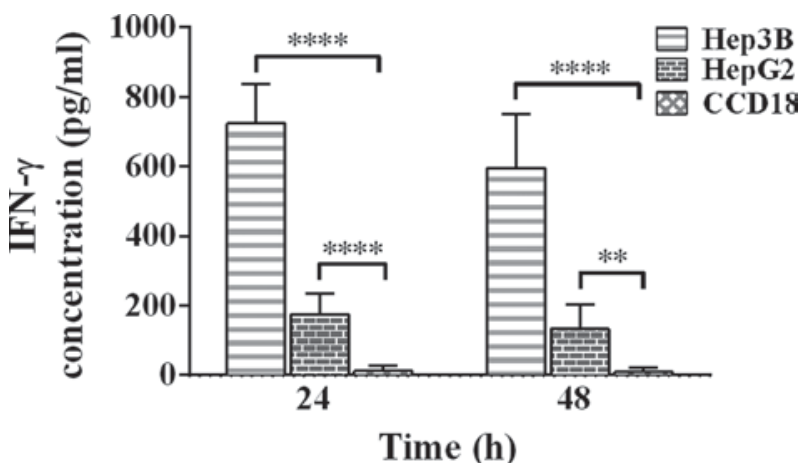

Figure 3. IFN-gamma levels secreted by CIK cells after incubation with one cell line for 24 and $48 \mathrm{~h}$. Results shown represent mean values after subtracting the absorbance caused by CIK cells alone. There was no contribution from target cells since they do not secrete IFN- $\gamma$. CCD18 cell line serves as a control. It is clear that CIK cells responded strongly to Hep3B cells, as the massive increase of IFN- $\gamma$ indicates. A response is still detectable when incubated with HepG2, but it is not as strong compared to the previously Hep3B-induced IFN- $\gamma$. The results shown are derived from data taken form 6 measurements $(\mathrm{n}=6) .{ }^{* *} \mathrm{P} \leq 0.01,{ }^{* * * * *} \mathrm{P} \leq 0.0001$. CIK, cytokine-induced killer.

IFN- $\gamma$ ELISA analysis. Fig. 3 shows the increase in IFN- $\gamma$ that is released from CIK cells once incubated with each cell line. After $24 \mathrm{~h}$, a massive surge is noticed once incubated with Hep3B cell line. On the other hand HepG2 caused less, yet significant, response. Moreover, levels or IFN- $\gamma$ have dropped as time passes, as the concentrations falls from 724 to 595, and from 175 to $133 \mathrm{pg} \bullet \mathrm{ml}^{-1}$ once incubated with Hep3B and HepG2 respectively. In contrast, a response can barely be seen against CCD18 control cell line reaching a peak of $12{\mathrm{pg} \bullet \mathrm{ml}^{-1}}^{-1}$ after $24 \mathrm{~h}$, and falling after that to almost zero.

\section{Discussion}

The vast majority of liver cancer cases worldwide are HCC. Its fast spread is due to viruses like Hepatitis B and C $(2,11)$. Although huge progress in terms of diagnosis has been achieved, the mystery of treating liver cancer once and for all remains unsolved. However, studies suggest that abrupt activation of the canonical Wnt//-Catenin pathway plays an important role in the pathogenesis process of liver cancer (14). This pathway is involved in cell division and proliferation. Mutations in any component belonging to this pathway may lead to cancer, as reported by Cieply et al (15). They proved that tumors with mutated $\beta$-catenin gene 1 (CTNNB1) had larger size and were more aggressive once compared to those without mutation. This is an indicator that this pathway is a promising target for future possible therapy. In previous studies, it was shown that both EA and CPX have the ability to eliminate cancer cells such as renal cell carcinoma and multiple myeloma by interfering with $W n t / \beta$-Catenin pathway (15-17). Identifying what kind of drugs and which concentration to use is essential and plants the primary seed to developing successful non-invasive treatment. For that reason we tried to do the same but with 
different type of cancer cells, namely HCC cell line Hep3B and hepatoblastoma cell line (HB) HepG2.

EA is being used as a loop diuretic and possesses antitumoral effects, presumably by breaking down the $\beta$-catenin-TCF complex in the nucleus (8). CPX has been approved as a topically-administered drug that has anti-fungal abilities. Furthermore, systemic administration of CPX had promising effects in countering tumor cells in many blood cancer cases, as proven in recent studies (18). Although the exact mechanism is still unravelled, it is thought to halt the cell cycle in the G1/S phase by inhibiting metal-dependent enzymes like the cyclin-dependent kinases (9). There was a strong induction of cellular apoptosis once EA and CPX were added to HCC and HB cell lines. Similarly, our findings agree with those of Lu et al (19), regarding lymphoma and myeloma cell lines. Also, similar results were obtained from drugs that have analogous structure to EA and CPX (20,21).

CIK cells were able to bind and kill cancer cells, while reacting less to normal fibroblasts. They also secreted higher levels of IFN- $\gamma$ once incubated with liver cancer cells, which argues that they are activated and responsive. IFN- $\gamma$ is one of the most important chemokines which is produced by effector T-cells and NK cells. It has antiviral property, and it is involved in the immune-regulation process. It has been already found by Yelei Guo (22) that IFN- $\gamma$ is secreted with and without stimulation by cancer cells. Our results confirm these statements.

As for the approach of combining EA and CPX with CIK cells, our data prove that EA and CIK cells work synergistically and as a consequence can be used against liver cancer cells Although CPX showed a similar response, it also caused apoptosis of a high number of normal non-cancerous cells. This is a big disadvantage which could counteract the idea of using it as a candidate for therapy. The reason why CPX killed normal cells is unknown. However, it is possible that after prolonged culture of normal cells few changes occur, which might lead to them being recognized as abnormal, and thus being attacked. Nevertheless, clinical trials that combine CIK cells with either dendritic cells or chemotherapy are currently being conducted (22).

It was proven that iron is crucial in the signaling pathway, and blocking it is an effective measure to hinder down-stream signaling. Not Only CPX but also various chemicals such as desferrioxamine, deferasirox and an identified series of acyl hydrazones have the ability to bind iron molecules and thus have the same inhibiting effect. They all decreased the levels of free cytoplasmic $\beta$-catenin. It was also mentioned that leukemic cells were more susceptible to iron chelation than normal cells (23). In our study, we did not assess the iron level in the cells. That's why further investigation is required.

As pointed out by Jiang et al (24), other important factors come to play a role such as RNF43 and ZNRF3, which decrease Wnt/ $\beta$-Catenin activity by inhibiting Frizzled. Furthermore, it has been proven that both RNF43 and ZNRF3 are indeed target genes for $\beta$-Catenin. This means that this process is a negative feedback loop. Also, they showed that inhibition of these factors resulted in higher levels of $\beta$-catenin in the cytosol in a pancreatic adenocarcinoma cell line. There are other attempts to target this pathway, as was demonstrated by Bar-Yehuda et al (25), that the drug CF102 increased GSK-3 $\beta$ expression, which in turn inhibited the down-stream components of the Wnt/ $\beta$-catenin pathway. A phase I/II clinical trial suggests that CF102 is safe to be used against HCC (26). Finally, there is certainly more about this pathway to be discovered; the more we learn about it, the more complex it appears to be.

In a study about CLL (18), it has been elucidated that each member of the Wnt/ $\beta$-Catenin pathway is involved in the pathogenesis. Despite investigation a different type of cells (liver cancer), the evidence is strong and supports the theory that the target genes for this pathway, like TCF/LEF, are drivers of malignancy and apoptosis survival. Pharmacological actions against the faulty members should be taken.

In the present study, EA and CPX have been used for the first time in the context of liver cancer. Although being preliminary results, it is concluded that at least EA could be used in lower doses, as a result of its low toxicity on CCD18 normal cell.

One limitation of this study is the fact that the effects of IFN- $\gamma$ in terms of cell growth inhibition have not been discussed. In addition, HepG2 cells were misidentified as HCC cells, while in fact they are Hepatoblastoma cells (27). Despite this error and that HCC and HB have several differences in their genetic characteristics, the pathway discussed here, Wnt/ $\beta$-Catenin, is aberrantly activated in both conditions. It has been proven that $\beta$-Catenin accumulates in the cytoplasm and the nucleus in HB and HCC (28). This supports the idea that having misidentified HepG2 as a HCC cell line will not affect the results of this study.

EA has strong synergistic anti-tumorous effect with CIK cells against HCC cells, while CPX affects normal cells as well. This implies that EA is a great drug for future usage, while CPX is not. There are many studies on multiple myeloma or leukemia, and rather a low number of studies on HCC and HB. More studies are warranted.

\section{Acknowledgements}

The authors would like to thank Ms. Anja Schmidt, Mrs. Isabel Cornez and Dr. Savita Bisht-Feldmann for providing general advice in the lab.

\section{Funding}

No funding was received.

\section{Availability of data and materials}

The datasets used and/or analyzed during the present study are available from the corresponding author on reasonable request.

\section{Authors' contributions}

AA performed the experiment, analysed the data, and wrote the manuscript. ISW designed the experiment, analysed the data and corrected the manuscript. HW analysed the data and corrected the manuscript. All authors read and approved the final manuscript.

\section{Ethics approval and consent to participate}

Blood samples were collected once ethical approval was obtained from the Ethical Committee of the University of 
Bonn (Bonn, Germany). In all cases written informed consent was obtained and the experiments were conducted in agreement with the Declaration of Helsinki.

\section{Patient consent for publication}

The manuscript does not include any identifying information, including names, initials, date of birth or hospital numbers, images or statements from any patients.

\section{Competing interests}

The authors declare that they have no competing interests.

\section{References}

1. Forner A, Llovet JM and Bruix J: Hepatocellular carcinoma. Lancet 379: 1245-1255, 2012.

2. Llovet JM, Burroughs A and Bruix J: Hepatocellular carcinoma. Lancet 362: 1907-1917, 2003

3. Venook AP, Papandreou C, Furuse J and de Guevara LL: The incidence and epidemiology of hepatocellular carcinoma: A global and regional perspective. Oncologist 15 (Suppl 4): S5-S13, 2010.

4. Bialecki ES and Di Bisceglie AM: Diagnosis of hepatocellular carcinoma. HPB Oxf 7: 26-34, 2005.

5. Lin S, Hoffmann K and Schemmer P: Treatment of hepatocellular carcinoma: A systematic review. Liver Cancer 1: 144-158, 2012

6. Tang B, Tang F, Wang Z, Qi G, Liang X, Li B, Yuan S, Liu J, Yu S and He S: Overexpression of CTNND1 in hepatocellular carcinoma promotes carcinous characters through activation of Wnt/ $\beta$-catenin signaling. J Exp Clin Cancer Res 35: 82, 2016.

7. Clevers $\mathrm{H}$ : Wnt/beta-catenin signaling in development and disease. Cell 127: 469-480, 2006.

8. Lu D, Liu JX, Endo T, Zhou H, Yao S, Willert K, Schmidt-Wolf IG, Kipps TJ and Carson DA: Ethacrynic acid exhibits selective toxicity to chronic lymphocytic leukemia cells by inhibition of the Wnt/beta-catenin pathway. PLoS One 4: e8294, 2009.

9. Zhou H, Shen T, Luo Y, Liu L, Chen W, Xu B, Han X, Pang J, Rivera CA and Huang S: The antitumor activity of the fungicide ciclopirox. Int J Cancer 127: 2467-2477, 2010.

10. Schmidt-Wolf IG, Negrin RS, Kiem HP, Blume KG and Weissman IL: Use of a SCID mouse/human lymphoma model to evaluate cytokine-induced killer cells with potent antitumor cell activity. J Exp Med 174: 139-149, 1991.

11. Sangiolo D: Cytokine induced killer cells as promising immunotherapy for solid tumors. J Cancer 2: 363-368, 2011.

12. Technologies DM: Inc. (n.d.). Cell Counting Kit-8 Retrieved Jan 24, 2017, from http://www.dojindo.com/store/ p/456-Cell-Counting-Kit-8.html
13. Schmidt M, Kim Y, Gast SM, Endo T, Lu D, Carson D and Schmidt-Wolf IG: Increased in vivo efficacy of lenalidomide and thalidomide by addition of ethacrynic acid. In Vivo 25: 325-334, 2011.

14. Vilchez V, Turcios L, Marti F and Gedaly R: Targeting Wnt/ $\beta$-catenin pathway in hepatocellular carcinoma treatment. World J Gastroenterol 22: 823-832, 2016.

15. Cieply B, Zeng G, Proverbs-Singh T, Geller DA and Monga SP: Unique phenotype of hepatocellular cancers with exon-3 mutations in beta-catenin gene. Hepatology 49: 821-831, 2009.

16. Von Schulz-Hausmann SA, Schmeel LC, Schmeel FC and Schmidt-Wolf IG: Targeting the Wnt/beta-catenin pathway in renal cell carcinoma. Anticancer Res 34: 4101-4108, 2014.

17. Schmeel LC, Schmeel FC, Kim Y, Endo T, Lu D and Schmidt-Wolf IG: Targeting the Wnt/beta-catenin pathway in multiple myeloma. Anticancer Res 33: 4719-4726, 2013.

18. Weir SJ, Patton L, Castle K, Rajewski L, Kasper J and Schimmer AD: The repositioning of the anti-fungal agent ciclopirox olamine as a novel therapeutic agent for the treatment of haematologic malignancy. J Clin Pharm Ther 36: 128-134, 2011.

19. Lu D, Zhao Y, Tawatao R, Cottam HB, Sen M, Leoni LM, Kipps TJ, Corr M and Carson DA: Activation of the Wnt signaling pathway in chronic lymphocytic leukemia. Proc Natl Acad Sci USA 101: 3118-3123, 2004.

20. Kim Y, Alpmann P, Blaum-Feder S, Krämer S, Endo T, Lu D, Carson D and Schmidt-Wolf IG: Increased in vivo efficacy of lenalidomide by addition of piroctone olamine. In Vivo 25: 99-103, 2011.

21. Kim Y, Alpmann P, Blaum-Feder S, Krämer S, Endo T, Lu D, Carson D and Schmidt-Wolf IG: In vivo efficacy of griseofulvin against multiple myeloma. Leuk Res 35: 1070-1073, 2011.

22. Guo Y and Han W: Cytokine-induced killer (CIK) cells: From basic research to clinical translation. Chin J Cancer 34: 99-107, 2015.

23. Song S, Christova T, Perusini S, Alizadeh S, Bao RY, Miller BW, Hurren R, Jitkova Y, Gronda M, Isaac M, et al: Wnt inhibitor screen reveals iron dependence of $\beta$-catenin signaling in cancers. Cancer Res 71: 7628-7639, 2011.

24. Jiang X, Hao HX, Growney JD, Woolfenden S, Bottiglio C, Ng N, Lu B, Hsieh MH, Bagdasarian L, Meyer R, et al: Inactivating mutations of RNF43 confer Wnt dependency in pancreatic ductal adenocarcinoma. Proc Natl Acad Sci USA 110: 12649-12654, 2013.

25. Bar-Yehuda S, Stemmer SM, Madi L, Castel D, Ochaion A, Cohen S, Barer F, Zabutti A, Perez-Liz G, Del Valle L, et al: The A3 adenosine receptor agonist CF102 induces apoptosis of hepatocellular carcinoma via de-regulation of the Wnt and NF-kappaB signal transduction pathways. Int J Oncol 33: 287-295, 2008.

26. Stemmer SM, Benjaminov O, Medalia G, Ciuraru NB, Silverman MH, Bar-Yehuda S, Fishman S, Harpaz Z, Farbstein M, Cohen S, et al: CF102 for the treatment of hepatocellular carcinoma: A phase I/II, open-label, dose-escalation study. Oncologist 18: 25-26, 2013.

27. López-Terrada D, Cheung SW, Finegold MJ and Knowles BB: Hep G2 is a hepatoblastoma-derived cell line. Human Pathol 40: 1512-1515, 2009

28. Buendia MA: Genetic alterations in hepatoblastoma and hepatocellular carcinoma: Common and distinctive aspects. Med Pediatr Oncol 39: 530-535, 2002. 